\title{
THE RUSSO-CHINESE WAR. By George Alexander Lensen. Tallahassee: Diplomatic Press, 1967. 315 pp. $\$ 15.00$.
}

The turn of the century was a difficult time for China. The Western Powers and Japan threatened her very existence. Russia, while claiming to be China's best friend, was in fact more determined than any other nation to expand her sphere of influence in China. The Boxer Rebellion served as a pretext to push that expansion another step forward. Boxer attacks upon the Russians and their properties in Manchuria provoked a Russian retaliation sufficient to bring Manchuria under Russian dominance for several years. A very small part of this development is singled out in this book for a detailed description. Mr. Lensen devotes his account mainly to military action between the Chinese and Russian soldiers and railwaymen in Manchuria. Even then he relies primarily upon Russian accounts, though without allowing himself to be unduly biased by this one-sidedness. The "war" was quite episodic. The Boxers do not seem to have had a general plan for a comprehensive, coordinated military attack against the Russians. The optimistic Russians had failed to anticipate Chinese actions and had to respond piecemeal and spontaneously. The pitiful unpreparedness of the Chinese was matched by the initially small size of the Russian forces. The encounters were more or less extensive skirmishes, providing the occasion for much individual heroism and suffering. For the reader who is fascinated by factual descriptions of military battles, this book will have some value. The reader who seeks enlightenment on the possible historical or political significance of this "Russo-Chinese War" cannot find it in this book. The author's concentration on such a very narrow and extremely specialized section of the Boxer events severely limits the value of the book. Only in the last chapter, dealing with the reactions of various foreign governments to the Manchurian events, is there a brief reference to the context in which they were taking place and to the political consequence they have had.

\section{WERNER LEVI University of Hawaii}

WITNESSES OF TSUSHIMA. By $J . N$. Westwood. Tokyo: Sophia University, in cooperation with the Diplomatic Press, Tallahassee, 1970. xiii, $321 \mathrm{pp}$. $\$ 15.00$.

Unlike many other episodes in Russian military history, the great naval battle of Tsushima, which undoubtedly marked the nadir of Russia's disastrous embroilment in the Russo-Japanese War, has not lacked chroniclers. Unfortunately, very few of the existing accounts of the tragic fate of the Second Pacific Squadron of Vice Admiral Z. P. Rozhdestvensky have been entirely objective or based on thoroughgoing research. The author of the present volume, who is perhaps best known for his studies of Russian railroads, has set out to correct the inaccuracies of earlier accounts of the battle and especially to dispel the notion that the Russian navy in 1905 was hopelessly inept and its opponent virtually flawless. Accordingly, in his excellent introductory chapter Westwood demonstrates that the Russian navy was by no means technically inferior to its rival and that in the naval action prior to Tsushima the Russians, although beset by some unusually bad luck, performed quite creditably.

For his account of the 18,000-mile voyage of the Second Pacific Squadron and of Tsushima itself, Westwood has employed an interesting approach. Thus, ex- 